\title{
Aging, Agency, and Self-Efficacy: A Phenomenological Case Study of an Older Couple
}

\author{
David A. Hernandez, PsyD, EdD, PhD \\ School of Behavioral Sciences, California Southern University, Irvine, California, United States \\ (iD) https://orcid.org/oooo-0oo1-6862-5718
}

Contact:dahernan@earthlink.net

\begin{abstract}
Researchers have found that the majority of older individuals want to remain in their own home as they age. However, respecting the right of older individuals to exert control over their life while ensuring their safety can be a difficult undertaking to achieve. The aim of this research was to understand the lived experiences of an older couple who are in cognitive decline but are trying to maintain personal agency. The issue was studied using Bandura's agency and self-efficacy theories as the theoretical framework. A phenomenological case study methodology was used. Participants were selected using a purposeful sampling strategy, and the sample was four individuals (father, mother, daughter, and grandson) from one family living at two separate residences. Data were collected using a mixed-methods approach. Qualitative data were collected by interviewing participants, and quantitative data were collected by administering a standardized cognitive assessment to the older individuals. Results indicated that the older couple were able to live independently because of the presence of the following five components: (a) adequate physical health; (b) adequate cognition, especially in the areas of memory and problem solving; (c) self-efficacy beliefs; (d) coping strategies to compensate for the declines in physical health and cognition due to aging; and (e) a support system to help the couple with activities they could no longer do on their own. In this study, each of the older individuals believed they could take care of themselves and wanted to live on their own. Independent living was only possible with significant assistance from family members.
\end{abstract}

Keywords: agency, self-efficacy, older individual, independent living, phenomenological case study

Date Submitted: June 14, 2021 | Date Published: November 30, 2021

\section{Recommended Citation}

Hernandez, D. (2021). Aging, agency, and self-efficacy: A phenomenological case study of an older couple. Journal of Social, Behavioral, and Health Sciences, 15(1), 309-328. https://doi.org/10.5590/JSBHS.2021.15.1.21

\section{Introduction}

Aging is a ubiquitous, progressive, and continuous process (Boccardi \& Boccardi, 2019). At one time, a commonly held aging stereotype was that "to be old is to be sick" (Potter et al., 2019, p. 276). However, in 1987, Rowe and Kahn first introduced the term "successful aging," which refers to those older individuals who retain high physical and cognitive functioning, remain free of disease and disability, actively engage in productive pursuits, and stay connected to others. This conceptualization of aging has been criticized as being 
overly optimistic (Martinson \& Berridge, 2015), and others have sought a compromise, preferring the term "healthy aging" (World Health Organization [WHO], 2015). With healthy aging, individuals enjoy functional health that enables well-being in older age (WHO, 2015).

In their sample of 27,013 Americans 51 years old and older, Lowsky et al. (2014) found that $28 \%$ of participants 85 years or older were in very good or excellent health. Additionally, $56 \%$ of the same participants in the 85 years and older age group had no health-based limitations in work or housework. Hence, a significant number of older individuals enjoy healthy aging and do not conform to the aging stereotype. Nevertheless, there is also a significant number of older individuals who are not aging successfully and do require assistance.

As the population ages (He et al., 2016), an increasing demand has been placed on the health-care system to care for those older adults who require assistance (Blumenthal et al., 2016). Caring for older adults in longterm care residential facilities has become a challenge due to a current shortage of skilled health-care professionals to care for older people in institutional-type settings (Kaye et al., 2010). Alders and Schut (2019) predicted there would be a shortage of long-term care residential facilities to accommodate the high-need older adults in the future because this segment of the population continues to grow. The United Nations, Department of Economic and Social Affairs, Population Division (2019) projected a 37.1\% increase in the world population of individuals 65 years old and older between 2020 and 2030. Individuals 85 years old and older, the oldest of the old, is the fastest growing segment of the population worldwide (Franceschi et al., 2019).

Researchers have found that older individuals would prefer to remain in their current home and "age in place" as long as possible rather than be moved to a new residence like a long-term care facility (Adekpedjou et al., 2018, Kane, 2005; Pynoos, 2018; Tao \& McRoy, 2015). However, as individuals age into older adulthood, they slow down, and activities in which these individuals engage daily become more challenging (Knickman \& Snell, 2002). Researchers have found that the decision to remove older individuals from their home setting and place them into a more restrictive long-term care facility depended on the older individuals' health and safety (Adekpedjou et al., 2018). If older adults are unable to provide adequate self-care or function independently in their home safely, then they may be unable to remain alone in their home.

As individuals age, many of the body's biological systems begin to malfunction or functional suboptimally, which may make it unsafe for older individuals to live alone. For example, in the nervous system, the depletion of neurotransmitters, loss of neurons, and slowing down of nerve conduction that occur with age trigger functional changes like impaired short-term memory and slower reaction times (Knight \& Nigam, 2017a). Additionally, there can be significant age-related changes in vision and hearing (Whitbourne \& Whitbourne, 2017). Visual impairment may impede older individuals from carrying out normal activities of daily living like preparing meals, bathing, grooming, reading, shopping, or going out, which compromises their independence (Taylor et al., 2016). Degenerative changes to the vestibular system result in dizziness, poor balance, and ultimately a greater fall risk (Knight \& Nigam, 2017b). Along with age-related changes to bones, joints, skeletal muscles, and the neurons that innervate the muscles, these alterations result in poorer mobility and an increase in fall risk (Bertoni et al., 2018; Whitbourne \& Whitbourne, 2017). Consequently, age-related changes in human biology negatively impact function, quality of life, and the safety of older individuals.

Besides the biological changes, alterations in psychological functioning occur with age. For example, processing speed, a proxy measure for attention (Schoen \& Holtzer, 2017), does slow down with age (Baghel et al., 2019). Driving performance is better with higher attentional capacity, and older individuals' lower attentional capacity is correlated with a higher incidence of car accidents (Cuenen et al., 2015). Moreover, older drivers who were involved in traffic accidents had a higher incidence of cognitive impairment (Withaar et al., 2000). The ability to drive contributes to a person's mobility, which is important to an older individuals' quality of life (Karthaus \& Falkenstein, 2016). Without mobility, the feeling of independence may be compromised. 
Two other changes in an older individual's mental capacity are a decline in fluid intelligence, the ability to analyze, integrate, and synthesize new information to solve problems (Whitbourne \& Whitbourne, 2017) and a decline in long-term episodic memory (Nyberg, 2017). Episodic memory is important for remembering events that have occurred to someone (Al-Qahtani, 2018) like remembering where one has put their keys or wallet. With the decline in the ability to solve novel problems that might arise during the course of a day and forgetting where one has put things, the challenges of maintaining one's independence are exacerbated.

The incidence of mild cognitive impairment (MCI) in individuals 60 years old and older has been estimated at 15\%-20\% worldwide (Petersen, 2016). One criterion for MCI is that an older individual recognizes and complains about their cognition; for example, they are having trouble remembering where they put things. Clinicians have further refined the criteria to include that the individual is still able to complete basic activities of daily living, such as bathing, toileting, dressing, feeding, and self-care, but the individual may have deficits in accomplishing instrumental activities of daily living (IADL), such as shopping, managing finances, keeping appointments, or using public transportation (Jekel et al., 2015). MCI falls somewhere along the continuum between normal cognitive aging and mild dementia (Petersen, 2016). MCI is the prodromal state of dementia, and when individuals develop MCI, they often begin to need help.

When older individuals need assistance to continue living safely at home, caregiver support is required to help them manage adequately on their own (Tao \& McRoy, 2015). Older adults who want to retain their independence (Caldeira et al., 2017) want to be consulted about their care (Chi et al., 2017). The level of care required may be limited to a few IADL (like housekeeping, yard maintenance, and grocery shopping), and these tasks may be easily completed by a child, other family member, or friend of the older individual (Tao \& McRoy, 2015). Approximately 75\% of unpaid caregivers in the United States were the son or daughter of the older individuals (Mendes, 2011). When an adult child of the older person is able to provide the needed caregiving services, then the older individual may continue to age in place for some additional time.

\section{Theoretical Framework}

The theory of self-agency was used to frame this study. Self-agency refers to the feeling that the individual is in control of their actions and the resultant outcomes (Aarts et al., 2009). Being in control of one's behavior suggests a self-awareness or consciousness of an inner self that creates desired goals and pursues them. The development of self-agency begins within the first year of life and becomes a more complex and central selfconcept with age (Knox, 2009). As individuals move into the late adulthood stage of life, however, they may develop poorer memories, health, and functional limitations, and therefore, these older individuals experience less sense of agency or control in their life (Infurna et al., 2018). The sense of self-agency develops and changes over one's lifetime.

The idea of personal agency and being in control of one's own fate has a long-standing history in society and the legal system (Aarts et al., 2009). To be one's own agent is “to exert intentional influence over one's functioning and the course of events by one's actions" (Bandura, 2012, p. 11). Nevertheless, society has a responsibility to maintain the safety of its citizenry (Chandhoke, 2007), so there may have to be a compromise between respecting older adults' desire for independence and restricting their self-agency for their own welfare.

A sense of self-agency is moderated by a sense of self-efficacy (Bandura, 1989). Bandura (2000) defined selfefficacy as an individual's belief that they are capable of controlling events in their lives because of their ability to perform in ways that give them this control. In his seminal article on self-efficacy, Bandura (1977) theorized that individuals will expend and sustain effort on coping behaviors, even in the face of obstacles, if there is an expectation that personal efficacy will be rewarded (i.e., goal achieved). Additionally, he argued that self-efficacy was a central mechanism of self-agency (Bandura, 1982). In causal tests, when individuals held higher selfperceptions of efficacy, they accomplished more tasks with lesser emotional arousal. One can deduce, therefore, 
that older individuals with higher perceptions of self-efficacy will be more likely to advocate for their continued independence and act accordingly compared to older persons with lower perceived self-efficacy.

\section{The Current Study: Goals}

The main goal of this research was to gain an understanding of the lived experience of an older couple who self-reported showing signs of cognitive impairment (e.g., memory problems) yet wished to continue living independently in their own home. The study also sought to understand the experiences of the older couple's daughter and grandson who lived within 5 miles but in a separate residence and who acted in a supportive role to the parents/grandparents. One final goal was to assess the cognitive functioning of the older couple.

\section{Methods}

\section{Participants}

For this mixed-methods phenomenological case study, there were four participants, all members of the same family. The older couple were husband Jack, 85 years old, and wife Sarah, 80 years old. Prior to his retirement at 59 years old, Jack was a quality control inspector of machine parts. Prior to her retirement at 58 years old, Sarah was a teacher's aide. The daughter, Chloe, was 49 years old and the grandson, Connor, was 21 years old. The closest other relation lived about 2,00o miles away.

\section{Procedures}

\section{Ethical Considerations and Recruitment}

I conducted the research in compliance with all APA ethical standards. Prior to data collection, the research was approved by Southern California University's Institutional Review Board. Using a purposeful sampling strategy, I spoke to colleagues within my organization to identify and recruit a family group that met the participant criteria of this research (i.e., an older couple living independently in their own home with signs of MCI and supportive family living nearby). After receiving agreement to participate from the family members, all participants signed informed consent forms.

\section{Data Collection}

I collected data in the naturalistic setting of the daughter's home through interviews and observations of the participants over multiple sessions. Bruderer-Hofstetter et al. (2020) suggested that a certain level of physical health and cognitive function is required to perform IADL, and an individual's ability to live independently requires performance of IADL. While working with patients with brain tumors, Oort et al. (2016) developed a questionnaire to assess the patient's ability to perform IADL. I adapted some items from the Oort et al. questionnaire to create a new, comprehensive interview protocol (see Appendix A) that would elicit data relevant to the older couple's experiences of living independently and maintaining their autonomy. I developed a second interview protocol (see Appendix B) to gather data relevant to the daughter's and grandson's supportive role. Additionally, I gathered objective data related to the older couple's cognitive functioning by administering the Woodcock-Johnson IV Tests of Cognitive Abilities to Jack and Sarah separately.

\section{Woodcock-Johnson IV Tests of Cognitive Abilities}

The Woodcock-Johnson IV Tests of Cognitive Abilities are a norm-referenced battery of tests, which assesses several areas of cognitive function (Reynolds \& Niileksela, 2015). For this study, Comprehension-Knowledge, Fluid Reasoning, Short-Term Working Memory, Long-Term Retrieval, Auditory Processing, and Cognitive 
Processing Speed were measured. A description of each of the six cognitive processes is shown in Table 1. Adequate psychometric properties of the Woodcock-Johnson IV Tests of Cognitive Abilities have been wellestablished (Reynolds \& Niileksela, 2015). Reliability was assessed using a test-retest procedure to determine the tests stability and a split-half procedure to determine the internal consistency of items on each subtest. Reliability coefficients were all above .70 , and most were .80 or above. Validity was assessed through multidimensional scaling to establish the tests' content validity, cluster analysis and confirmatory factor analysis to establish the tests' internal structure, and correlational analysis to establish concurrent validity.

Table 1. Description of Cognitive Processes

\begin{tabular}{|c|c|}
\hline Cognitive process & Description \\
\hline Comprehension-Knowledge & $\begin{array}{l}\text { The ability to understand spoken language and communicate } \\
\text { knowledge }\end{array}$ \\
\hline Fluid Reasoning & The ability to solve novel problems using reason \\
\hline Short-Term Working Memory & $\begin{array}{l}\text { The ability to take in, hold in immediate awareness, and } \\
\text { manipulate information to accomplish a task }\end{array}$ \\
\hline Long-Term Retrieval & The ability to store and retrieve information easily \\
\hline Auditory Processing & The ability to interpret, combine, and distinguish sounds \\
\hline Cognitive Processing Speed & The ability to complete cognitive tasks rapidly \\
\hline
\end{tabular}

\section{Data Analysis}

I took field notes during the interviews and typed them into narrative paragraphs as soon as the interviews were completed. The audio recordings were transcribed, and my initial read-through of the transcribed interviews served to verify the accuracy of the transcription and identify preliminary phrases and sentences related to participants' experiential feelings, details, and meanings about independent living. I assigned codes to the meaningful phrases and sentences. In subsequent read-throughs, I analyzed the transcripts simultaneously side by side to identify common codes across the participants. Subsequently, I combined codes into common themes.

\section{Results}

From Jack's and Sarah's responses to the interview protocol questions, five themes emerged related to their success in independent living: physical health; cognition, including problem-solving ability and memory; selfefficacy beliefs; coping strategies; and a support system, including both emotional and tangible supports.

\section{Theme 1: Physical Health}

Both Jack and Sarah reported being in good physical health. When asked about her health over the past month, Sarah stated, "I've been pretty healthy. The only thing that I have noticed in my health is my memory. Other than that, I feel great." When discussing his health over the past 30 days, Jack was vaguer and said, "I can't complain."

Chloe believed that her parents physical health was okay. She mentioned that they took some medication daily. Her mother took a pill for depression/anxiety and a pill to help with her memory. Daily, her father took a pill for high blood pressure, one for high cholesterol, one for thinning the blood, and one to help him with his memory. Chloe stated, "But I think that's pretty normal for that age." 
Connor was concerned about his grandparents' physical health. He commented that they had not been feeling well. Connor attributed this, in part, to their cultural heritage. They are Irish, and the Irish like to drink lots of tea. "They will drink between one and 10 cups of tea a day and get completely dehydrated. And then they'll wonder, 'Why are we dehydrated? Why are we not feeling good?" Moreover, Connor stated that the pandemic had adversely affected his grandparents' health, "It is taking their final years away." His grandparents used to go back to visit family in Ireland every year, but because of the pandemic, they were unable to travel to Ireland last year and would unlikely be able to go that current year.

\section{Theme 2: Cognition}

Sarah articulated that she had recently been having problems with her memory (cognition). She had trouble remembering where she put things. Sarah joked when she provided an example of what she meant by memory problem. She might ask, "Where did I put those keys, Jack?” [And Jack's response would be], "You know, exactly where you left them!" Sarah gave another example of a memory issue by describing what might happen when she was straightening up the house:

I might put something in the wrong place, or not where I am familiar with it. And then when I go to look for it, I can't find it. So, finding things, like keys, things like that, and hearing aids, those are things that I find very difficult to remember.

Jack struggled to explain his memory problems. He could not remember if he had trouble remembering. He asserted, however, that he was taken care of and did not lack for anything.

Sarah demonstrated an ability to problem solve (cognition). She knew what to do if she got lost (i.e., "I probably would have to stop someone in the store and ask, 'May I use your phone?'”). She affirmed that she had her daughter's phone number memorized. Sarah also knew how she could get somewhere when she needed to go by car (i.e., phone her daughter for a ride, but if her daughter was busy, then Sarah would have her daughter order her an Uber ride). She has taken many Uber rides that her daughter ordered but not since the COVID-19 pandemic.

In terms of her parents' cognition, Chloe had definite concerns for their memory. Chloe reported that her mother loses or misplaces things (e.g., cell phone, which was lost and not replaced, her hearing aide, and her wallet). Chloe tried to teach her mother how to use a cell phone to order an Uber, but her mother was unable to remember how to do it. About 3 years ago, Chloe took away the keys to Jack's and Sarah's car after Sarah was involved in a car accident, in which Sarah was at fault. Chloe believed that her mother was still capable of driving, but she expressed a concern about whether her mother's driving would be safe. Jack lost his driver's license approximately 10 years ago after he had a fainting spell. The emergency room doctor told him not to drive in case he had another fainting spell while driving, and Jack has not driven since that time.

Sarah engaged in activities to keep her mind nimble. Chloe shared, "She reads, does crossword puzzles, and has asked me to buy her coloring books to color in." On the other hand, Jack did none of those things. He tended to watch television for about 5 hours a day.

Chloe expressed a concern over her father's new behavior of wandering away from home. Recently, he had wandered off three times. She said, "One neighbor caught him once, and then like [another time] he was almost at Southwest Coast Mall when I found him.” In the most recent occurrence of wandering, Jack was walking to the airport. He was convinced that he had purchased a ticket to fly home to Ireland.

At times, Chloe questioned her mother's ability to care for the household. Chloe explained that Sarah thought the house was clean when it was actually dirty, or Chloe found Sarah crying because she had lost her hearing aid, which was not found for 4 days. According to Chloe, similar events like the two cited happened on a daily 
basis. Chloe confirmed Sarah's statement about Sarah's memory not being good and thus, Sarah did not remember the struggles she had to maintain her independence.

Connor was concerned about his grandfather's cognition. Connor said that Jack "has his good days and bad days, but there's a lot more bad days than good days." Jack taught Connor to play golf, which was something Connor enjoyed doing with his grandfather. His grandfather did not play golf anymore; however, "he's come and watched me play maybe twice this last year." Additionally, his grandfather has walked away from the home on his own and has gotten lost, with no thought of the possible danger or consequences. Connor stated:

My grandpa has had a few cases where he just walked out on his own, and where he has ended up at Southwest Coast Mall, or where he has ended up at CVS, and we don't know where he is.

\section{Theme 3: Self-Efficacy}

Both Jack and Sarah believed that they were capable of taking care of themselves and living on their own. Sarah indicated that she could take care of herself: "For [taking care of] my personal hygiene, I feel very good." She asserted that she could provide some limited help to Jack: "I'd be able to help him up, but then I would probably, if he needed [more] help, then I would call somebody. If it's just a fall, that would be okay. I could help him with that." When asked about the challenges of living alone, Sarah responded, "I think we are okay, except if we need [medical/dental] appointments, or grocery shopping, or that kind of thing ... But as far as making breakfast or food, I can still do that.”

Jack stated, "I think that I could take care of myself, but it's just something that I am not looking forward to." He did not believe, however, that he could take care of his wife if she needed help. Jack's self-efficacy belief was limited to his ability to care for himself alone.

Chloe believed that her mother was, in fact, capable of living on her own (with some support), and she recognized that her mother felt she was capable of taking care of herself and her husband, Chloe's father. Nevertheless, Chloe stated, "I think my mom's perception of things is a little off of the reality of what she's capable of doing," which meant Chloe thought Sarah was overly optimistic about her self-efficacy.

\section{Theme 4: Coping Strategies}

Sarah recognized that with age came limitations, and, as a result, she needed to do things differently. For example, she discussed her approach to paying bills.

Well, what I do is, when the bills come in. I write the checks right away. If I don't, it might get misplaced.

So, it is better if I do it right then. If I don't, I could possibly forget about it.

Additionally, rather than cooking meals every day like she did when she was younger, she prepared enough food for more than one meal. It saved her time and energy to reheat food that she had already prepared the day before.

\section{Theme 5: Support System}

Both Jack and Sarah discussed the need for additional support. Jack explained that Sarah took on tasks that he no longer did (e.g., "My wife takes care of them [finances]. I used to, but not anymore.”). He also acknowledged that his wife took care of him. 
Sarah highly praised her daughter's and grandson's efforts in supporting her and Jack. She described suffering from loneliness and depression, but "whenever Chloe or Connor comes over, it's kind of a bright spark to the day." Sarah also expressed that she did not know what they (Sarah and Jack) would do without Chloe. Chloe did the grocery shopping to make sure they always had more than enough food in the house. Chloe scheduled and took them to their medical/dental appointments. Connor took them on outings, so they got out of the house.

Chloe said that she provided a great deal of support to her parents, "Grocery shopping, medications, doctor's appointments, everything. The only thing I don't help with really is laundry and house cleaning." Chloe recounted a recent banking transaction that her mother undertook. Sarah intended to withdraw \$400 from her bank account, but completed the withdrawal slip incorrectly and withdrew $\$ 4,000$. Later when Chloe questioned her mom, Sarah was too embarrassed to show Chloe the envelope of money the teller had given Sarah. Although Sarah still managed the older couple's finances, Chloe provided oversight of the transactions as needed.

In discussing what would happen if one spouse passed away before the other, Chloe stated, "If she [my mom] passes away before my dad, that's easy, I would just move him in here. I mean, I would have to hire care, but he is easier than my mom because my mom's depression is very challenging." The caregiver who Chloe would hire would care for her father during the day while she was working. Moreover, Chloe noted some recent problematic behavior, "My dad has turned angry. He will get angry now, so that's new, but I know that that is part of the process. And my mom is aware when he does get violent, he will need to go [into a home]." This new angry behavior was concerning to both Chloe and Sarah.

Chloe had discussed other living arrangements with her parents, but they were unwilling to consider them at that time. Sarah had an older sister living in Ireland, who was still very sharp mentally and very capable of independent living, and Chloe suggested that Sarah might enjoy living with her sister. Also, Chloe discussed with her parents the options of moving into a retirement home facility or living in her home. Jack and Sarah were not open to those suggestions at the time.

Connor shared that his grandmother got stressed and nervous, and then just wanted to go back to bed. He provided support by taking his grandparents out of the house to get them walking or moving about. He stated:

Driving, feeding them, getting them out of the house, getting their medication, getting them groceries, getting them out just moving, like just getting them out on a simple walk, or [doing] little things. I mean, fixing their TV. That always happens; it always gets messed up.

Connor opined that in the near future, his grandparents likely would need alternative living arrangements, "I think that someone will eventually have to move into our house, or they will have to move into a facility." If they moved into Chloe's house, a trained professional would be required since Connor would not want to toilet his grandmother. He also stated that he would have no problem moving in with his grandparents to care for them if they wanted to remain in their home:

Now whether that is me moving in with them or if that is a certified professional [moving in with them], I don't know that. I have no problem doing it, and I have told them that, but my concern would be just they're getting along, or their getting by on a day-to-day basis.

\section{Personal Impact on Family Caregivers}

Chloe asserted that she no longer had a life of her own, "I mean, I kind of don't have a life, to tell you the truth. I think I have lost some friends, too, because of it." Providing the needed support to her parents meant that her free time was significantly impacted by the care she gave to them. She admitted that she could not have done it without her son's involvement. Her son's school (university) schedule allowed him to be "on call" during the week while Chloe was at work. Chloe stated that Connor took her parents/his grandparents on outings (e.g., to a 
restaurant for lunch, to the shopping mall to walk around, etc.) two to three times a week. Chloe did the grocery shopping for her parents on Saturdays and took her parents to church on Sundays and, as a result, she had not been available to spend time with her friends. Additionally, she felt stressed and stated, "I'm just tired all the time because I don't feel like I have any downtime" to be able to focus on her own self-care needs.

Connor's grandparents' decline drew him closer to them, "I have no problem being over there within a minute of them calling." He spoke fondly of his relationship with his grandparents. "I am close to two people who I care very deeply for, and they care deeply for me.” He talked about his other friends going out and doing other things, but those friends were not close to their families like he was with his. Connor did not regret the greater demand on his time that his aging grandparents required.

\section{Woodcock-Johnson IV Tests of Cognitive Abilities}

The scores obtained for the assessed cognitive domains are displayed in Table 2. Jack's cognitive function was poor with a General Intellectual Ability composite score in the very low range. His Fluid Reasoning ability, which measures problem-solving ability, was in the low average range. His score was 89, and a score of 90 is in the average range. With a confidence interval of 83-95, it is possible that Jack's problem-solving ability was actually in the average range. Jack's Fluid Reasoning was an area of cognitive strength for him.

Jack's Comprehension-Knowledge, which measures knowledge, facts, and skills acquired during his lifetime, was in the low range. He scored within the very low range for the remaining abilities assessed (i.e., ShortTerm Memory, Long-Term Storage and Retrieval, and Auditory Processing). Considering his scores on the broad cognitive abilities that were measured by the Woodcock-Johnson IV Tests of Cognitive Abilities, it was unlikely that Jack had adequate cognition to care for himself safely on his own.

Table 2. Jack's and Sarah's Cognitive Testing Results

\begin{tabular}{lcll}
\multicolumn{1}{c}{ Broad ability/IQ } & $\begin{array}{c}\text { Standard } \\
\text { score } \\
\text { Jack's scores }\end{array}$ & Classification & $\begin{array}{c}\text { Confidence } \\
\text { interval }\end{array}$ \\
Comprehension-Knowledge & 71 & Low & \\
Fluid Reasoning & 89 & Low Average & \\
Short-Term Working Memory & 55 & Very Low & \\
Long-Term Retrieval & 47 & Very Low & \\
Auditory Processing & 69 & Very Low & \\
Cognitive Processing Speed & 40 & Very Low & $53-63$ \\
General Intellectual Ability & 58 & Very Low & $70-81$ \\
Brief Intellectual Ability & 75 & Low & \\
& Sarah's scores & \\
Comprehension-Knowledge & 81 & Low Average & \\
Fluid Reasoning & 89 & Low Average & \\
Short-Term Working Memory & 103 & Average & \\
Long-Term Retrieval & 87 & Low Average & \\
Auditory Processing & 87 & Low Average & \\
Cognitive Processing Speed & 64 & Very Low & \\
General Intellectual Ability & 89 & Low Average & $82-95$ \\
Brief Intellectual Ability & 97 & Average & $91-102$
\end{tabular}


Sarah's cognitive function was likely in the average range; however, she did achieve a composite score of 89 for General Intellectual Ability, which is in the low average range (just one point below the beginning of the average range). Another measure of intellectual ability is the Brief Intellectual Ability composite score. On that measure of cognitive functioning, she scored 97 , which is solidly in the average range (the entire confidence interval for the score she obtained is within the average range). When Sarah's General Intellectual Ability composite score and her Brief Intellectual Ability composite score are considered together, it is reasonable to conclude Sarah had average cognitive function.

Sarah's Short-Term Working Memory was an area of strength, and Processing Speed (sustained attention) was an area of weakness. It is important to note that Short-Term Working Memory is the ability to hold information in immediate awareness and use it within a few seconds. It is not the memory individuals use to remember where they left their keys or where they put their wallet. Remembering events like where one has left their keys or put their wallet is explicit, episodic long-term memory, and that ability is measured by the Long-Term Storage and Retrieval ability of the Woodcock-Johnson IV Tests of Cognitive Abilities. Sarah's Long-Term Storage and Retrieval, Fluid Reasoning, Comprehension-Knowledge, and Auditory Processing abilities were in the low average range. Based on Sarah's cognitive profile, she likely had the cognitive abilities required to live independently.

\section{Discussion}

Jack and Sarah were an older couple who wanted to remain in the family home and live independently for as long as possible. Their desire to age in place was consistent with the literature (e.g., Adekpedjou et al., 2018; Kane, 2005; Pynoos, 2018; Tao \& McRoy, 2015). They realized that they had physical and cognitive limitations, yet they believed they had the ability (self-efficacy) to continue living on their own. Sarah had developed some coping strategies to help her adjust to her physical and cognitive limitations, whereas Jack was happy to let his wife (and others) take care of him. Jack and Sarah relied on a number of individuals to support them in their decision to age in place. Their daughter Chloe and grandson Connor provided the lion's share of that support; however, Chloe also hired help like a house cleaner and yard maintenance person. Chloe and Conner indicated that the amount of support they provided changed over time. As Jack and Sarah lost interest or became incapable of completing tasks, they relied on help from others (i.e., Chloe, Connor, and paid helpers).

Figure 1 provides a visual representation of the five themes which emerged from the data. Two important themes for safely maintaining one's independence are physical health and adequate cognition. As argued by Bruderer-Hofstetter et al. (2020), a certain level of physical health and cognitive function is required to perform IADL, and the performance of IADL by the older individual is required for independent living. Moreover, there appears to be a reciprocal relationship between one's physical and cognitive health and one's efficacy beliefs, which in turn motivates the older individual to use effective coping patterns for self-care (Tovel et al., 2019). The interaction among the first four themes, physical health, cognition, self-efficacy beliefs, and coping strategies, appeared to determine the couple's ability to safely live independently.

The findings of a study by Knowles et al. (2020) suggested that an individual's poor health, weak self-efficacy beliefs, and inadequate coping strategies, were associated with greater anxiety and poorer quality of life. An individual will suspend efforts in using coping behaviors if they do not believe they have the self-efficacy in accomplishing the task (Bandura, 1977). Therefore, when one's coping strategies fail and an individual no longer believes they are capable of completing tasks independently, those tasks are given over to the support system that slowly grows in magnitude over time. The process of change from independent living to dependent living seems to occur slowly over time and appears analogous to the sand slipping through the opening of an hourglass. As failing physical health and cognition lead to weaker self-efficacy beliefs and less 
effective coping strategies, activities of daily living are relegated to the individual's support system. Eventually with time, the older individual will be unable to live independently on their own.

Figure 1: Visual Representation of the Themes

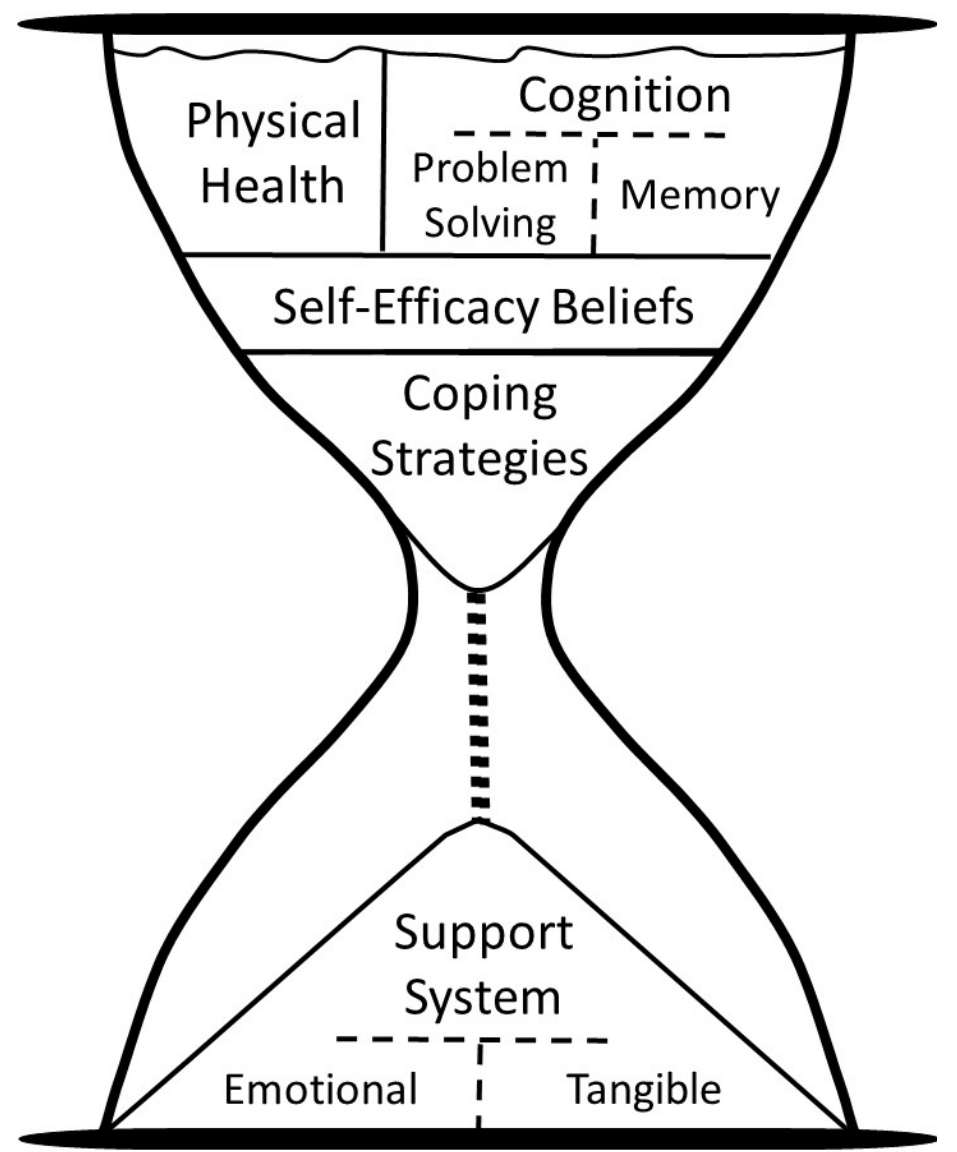

In terms of the impact on caregivers, not uncommonly, Chloe (the daughter) was providing care for her aging parents (Mendes, 2011). Chloe felt she had limited free time and had lost friends because of the amount of time she has had to devote to the care of her parents. She felt stressed and constantly fatigued, unable to focus on her own self-care. Consistent with the literature, providing care to an older family member can be stressful on the caregiver, which may result in negative effects on physical health (Amankwaa, 2017).

Conversely, Connor (the grandson of Jack and Sarah) felt their decline drew him closer to the grandparents he loved. He did not regret the extra draw on his time that was required in supporting his grandparents. He claimed that his friends did not understand because they did not have the same relationship with their families as he did with his. Hamill (2012) found that grandchildren who had greater affection for their grandparents provided more caregiving when grandparents needed it. Moreover, in their study of caregiving grandchildren, Fruhauf and Orel (2008) found that three-quarters of the participants had positive connections with their grandparents and positive feelings toward their caregiving role.

\section{Limitations}

The sample size of this study was small, limited to one family, which limits generalizability. Moreover, the research was completed in the natural setting of the daughter's home, which limits replicability of the study. 
Because I used a purposeful sampling strategy, selecting the participants who I believed most representative of the phenomenon of interest, my belief may have been incorrect and other participants would have better informed this research study. Qualitative researchers use observations and interviews to collect data; organize, read, and reflect on the data; identify codes and the themes in the data; and finally, interpret the meaning of the data (Bogdan \& Biklen, 2006; Creswell \& Creswell, 2017). It is possible, therefore, that I misinterpreted the data due to my own biases. However, I attempted to use the participant's meaning of ideas, words, and phrases (including direct quotes) to establish the credibility of the research.

\section{Implication for Practice}

When older individuals are capable of being their own agents and making decisions about their living arrangements that result in safe and healthy living, they have the legal right to do so. Family members and health-care professionals should respect the right of the older person to remain in their own home. Safety should be the overriding consideration. Older individuals need to be physically healthy, which means they need to have adequate joint flexibility and mobility for self-care and undertaking basic activities of daily living (ADL). Additionally, older individuals need to have adequate mental health, which means most of their various cognitive abilities should be at least in the low average range. Once the two foundational requirements of adequate health and cognition are met, then other factors should be considered.

If older individuals believe they are capable of living independently, the family member and/or health-care professional should consider the efficacy of the older person to do so. Older individuals may have developed strategies to cope or offset the physical and cognitive limitations brought on by age. If an older individual cannot complete basic ADL independently, it should not automatically mean that the older person needs to be removed from their home and placed in a more restrictive environment. A family member or friend may be able to provide the support needed for the older individual to complete basic ADL, or the necessary support can be hired (e.g., a health-care worker to bathe a parent three times a week). In the present study, family members had good insight into whether their older family members were capable, especially since both younger family members spent a lot of time caring for their older family members.

Finally, the amount of additional support an older individual may need must also be considered. Caregivers must always be concerned with their own self-care. If the level of commitment is too taxing on the caregiver's time or too stressful, then the older individual is not helped if the caregiver becomes ill (physically or emotionally) as a result. The goal is to honor the older individual's self-agency if their decision to age in place can be done safely when considering their physical health, cognition, self-efficacy, coping strategies, and required level of support.

It is important for the family caregiver and/or health-care professional to listen to the wishes of the older individual, but be prepared to override those wishes if safety is a concern. Often an older individual may not have good cognition and, therefore, may not have insight into their own limitations and also may have poor judgment. Be sure, however, to clearly communicate to the older individual that their wishes have been heard and taken into consideration. Be prepared to provide specific reasons for not allowing the older individual to continue living independently if that is the decision.

\section{Recommendations for Research}

This study provided insight into the lived experience of one family living in the United States in which the older couple was living independently and both older individuals were showing signs of cognitive decline. The results of this study, although significant in terms of contributing to the understanding of the thoughts, feelings, and actions of older individuals exercising their self-agency, are based on a small sample. Additional 
phenomenological research should be undertaken to expand this initial study using a larger sample size. The southern California coast has a mild climate year round. Couples from other climates (e.g., the Northeast) should be included in the sample, as well, to determine whether climate has an effect on older couples' ability to live independently.

It is likely not practical to administer a cognitive assessment to all older individuals, such as the WoodcockJohnson IV Tests of Cognitive Abilities. It is too labor intensive and time consuming to administer. Nevertheless, because cognitive abilities like memory and problem solving are important to safe independent living, a quick cognitive test could be used, as long as the test measures aspects of problem solving (reasoning) and memory. Other shorter cognitive tests that could be used include the Short Test of Mental Status or Cognitive Abilities Screening Instrument, which take between 5 and 15 minutes to administer and assess both reasoning and memory (Cullen et al., 2007).

In the current research, the wife was key to the couple's ability to continue independent living in their home. Despite her spouse living with her, the wife experienced loneliness and depression. Another vein of research that should be pursued is to determine the lived experience of the older individual who lives alone. Is the lived experience of the older male living alone different from the older female living alone?

\section{Conclusion}

The collective insights provided by the four participants on the lived experiences of an older couple exercising self-agency and living independently revealed five components that were present. The couple needed (a) adequate physical health; (b) adequate cognition, especially in the areas of memory and problem solving; (c) self-efficacy beliefs; (d) coping strategies to compensate for the declines in physical health and cognition due to aging; and (e) a support system to help the couple with activities they could no longer do on their own like grocery shopping and getting to the doctor's office for medical appointments. In this study, each of the older individuals believed they could take care of themselves and wanted to live on their own; however, independent living was only possible with significant assistance from family members. Additionally, the couple was showing signs of cognitive decline, and the most troublesome sign was that there was evidence of moderate cognitive impairment of the older male.

In reality, this older couple was living on their own, but there was a shared agency. For example, the couple were making the decision to live in their own home by themselves, but the daughter was making a number of decisions as well. For instance, the daughter took away her mother's car keys so her mother could not drive due to concerns for the safety of other drivers. Furthermore, the daughter monitored her parents' finances closely and intervened when necessary. However, the stress and time commitment were having a negative impact on the daughter's mental state. Whether the older couple will be able to continue living independently will be a function of the available support system. 


\section{References}

Aarts, H., Custers, R., \& Marien, H. (2009). Priming and authorship ascription: When nonconscious goals turn into conscious experiences of self-agency. Journal of Personality and Social Psychology, 96(5), 967-979. https://doi.org/10.1037/aoo15000

Adekpedjou, R., Stacey, D., Brière, N., Freitas, A., Garvelink, M. M., Turcotte, S., Menear, M., Bourassa, H., Fraser, K., Durand, P. J., Dumont, S., Roy, L., \& Légaré, F. (2018). "Please listen to me": A crosssectional study of experiences of seniors and their caregivers making housing decisions. PloS ONE, 13(8), Article e0202975. https://doi.org/10.1371/journal.pone.0202975

Alders, P., \& Schut, F. T. (2019). Trends in ageing and ageing-in-place and the future market for institutional care: Scenarios and policy implications. Health Economics, Policy and Law, 14(1), 82-100. https://doi.org/10.1017/S1744133118000129

Al-Qahtani, A. A. (2018). The effect of age on memory. In Improving educational quality toward international standard: Volume 1: ICED-QA (pp. 173-177). https://doi.org/10.5220/o008682601730177

Amankwaa, B. (2017). Informal caregiver stress. ABNF Journal, 28(4), 92-95.

Baghel, M. S., Singh, P., Srivas, S., \& Thakur, M. K. (2019). Cognitive changes with aging. Proceedings of the National Academy of Sciences, India Section B: Biological Sciences, 89(3), 765-773. https://doi.org/10.1007/s40011-017-0906-4

Bandura, A. (1977). Self-efficacy: Toward a unifying theory of behavioral change. Psychological Review, 84(2), 191-215. https://doi.org/10.1037/0033-295x.84.2.191

Bandura, A. (1982). Self-efficacy mechanism in human agency. American Psychologist, 37(2), 122-147. https://doi.org/10.1037/0003-066X.37.2.122

Bandura, A. (1989). Human agency in social cognitive theory. American Psychologist, 44(9), 1175-1184. https://doi.org/10.1037/0003-066X.44.9.1175

Bandura, A. (2000). Self-efficacy. In A. E. Kazdin (Ed.), Encyclopedia of psychology (Vol. 7, pp. 212-213). American Psychological Association. https://doi.org/10.1037/10522-094

Bandura, A. (2012). On the functional properties of perceived self-efficacy revisited. Journal of Management, 38(1), 9-44. https://doi.org/10.1177/0149206311410606

Bertoni, M., Maggi, S., \& Weber, G. (2018). Work, retirement, and muscle strength loss in old age. Health Economics, 27(1), 115-128. https://doi.org/10.1002/hec.3517

Blumenthal, D., Chernof, B., Fulmer, T., Lumpkin, J., \& Selberg, J. (2016). Caring for high-need, high-cost patients-an urgent priority. New England Journal of Medicine, 375(10), 909-911. https://doi.org/10.1056/NEJMp1608511

Boccardi, M., \& Boccardi, V. (2019). Psychological wellbeing and healthy aging: Focus on telomeres. Geriatrics, 4(1), Article 25. https://doi.org/10.3390/geriatrics4010025

Bogdan, R. C., \& Biklen, S. K. (2006). Qualitative research for education: An introduction to theories and methods (5th ed.). Pearson.

Bruderer-Hofstetter, M., Sikkes, S. A. M., Münzer, T., \& Niedermann, K. (2020). Development of a model on factors affecting instrumental activities of daily living in people with mild cognitive impairment-a Delphi study. BMC Neurology, 2O(1), Article 264. https://doi.org/10.1186/s12883-020-01843-9

Caldeira, C., Bietz, M., Vidauri, M., \& Chen, Y. (2017, February 25-March 1). Senior care for aging in place: Balancing assistance and independence [Conference session]. ACM Conference on Computer 
Supported Cooperative Work and Social Computing, Portland, OR, United States. https://doi.org/10.1145/2998181.2998206

Chandhoke, N. (2007). Engaging with civil society: The democratic perspective. Non-Governmental Public Action Programme, London School of Economics. https://www.researchgate.net/publication/265142795_Engaging_with_Civil_Society_The_Democra tic_Perspective

Chi, W. C., Wolff, J., Greer, R., \& Dy, S. (2017). Multimorbidity and decision-making preferences among older adults. Annals of Family Medicine, 15(6), 546-551. https://doi.org/10.1370/afm.2106

Creswell, J. W., \& Creswell, J. D. (2017). Research design: Qualitative, quantitative, and mixed methods approaches (5th ed.). SAGE Publications.

Cuenen, A., Jongen, E. M. M., Brijs, T., Brijs, K., Lutin, M., Van Vlierden, K., \& Wets, G. (2015). Does attention capacity moderate the effect of driver distraction in older drivers? Accident Analysis and Prevention, 77, 12-20. https://doi.org/10.1016/j.aap.2015.01.011

Cullen, B., O’Neill, B., Evans, J. J., Coen, R. F., \& Lawlor, B. A. (2007). A review of screening tests for cognitive impairment. Journal of Neurology, Neurosurgery, and Psychiatry, 78(8), 790-799. https://doi.org/10.1136/jnnp.2006.095414

Franceschi, C., Ostan, R., Mariotti, S., Monti, D., \& Vitale, G. (2019). The aging thyroid: A reappraisal within the geroscience integrated perspective. Endocrine Reviews, 4O(5), 1250-1270. https://doi.org/10.1210/er.2018-00170

Fruhauf, C. A., \& Orel, N. A. (2008). Developmental issues of grandchildren who provide care to grandparents. International Journal of Aging and Human Development, 67(3), 209-230. https://doi.org/10.2190/AG.67.3.b

Hamill, S. B. (2012). Caring for grandparents with Alzheimer's disease: Help from the "forgotten" generation. Journal of Family Issues, 33(9), 1195-1217. https://doi.org/10.1177/0192513X12444858

He, W., Goodkind, D., \& Kowal, P. (2016). An aging world: 2015: International population reports. U.S. Census Bureau. https://www.census.gov/content/dam/Census/library/publications/2016/demo/p95-16-1.pdf

Infurna, F. J., Kappes, C., \& Fraire, N. (2018). Long-term antecedents of constraints and mastery: Findings from the Health and Retirement Study. Psychology and Aging, 33(6), 965-974. https://doi.org/10.1037/pagoooo281

Jekel, K., Damian, M., Wattmo, C., Hausner, L., Bullock, R., Connelly, P. J., Dubois, B., Eriksdotter, M., Ewers, M., Graessel, E., Kramberger, M. G., Law, E., Mecocci, P., Molinuevo, J. L., Nygård, L., OldeRikkert, M. G., Orgogozo, J.-M., Pasquier, F., Peres, K., Salmon, E. . . Frölich, L. (2015). Mild cognitive impairment and deficits in instrumental activities of daily living: A systematic review. Alzheimer's Research and Therapy, 7(1), Article 17. https://doi.org/10.1186/s13195-015-0099-o

Kane, R. L. (2005). Changing the face of long-term care. Journal of Aging and Social Policy, 17(4), 1-18. https://doi.org/10.1300/Jo31v17no4_01

Karthaus, M., \& Falkenstein, M. (2016). Functional changes and driving performance in older drivers: Assessment and interventions. Geriatrics, 1(2), 12-20. https://doi.org/10.3390/geriatrics1020012

Kaye, H. S., Harrington, C., \& LaPlante, M. P. (2010). Long-term care: Who gets it, who provides it, who pays, and how much? Health Affairs, 29(1), 11-21. https://doi.org/10.1377/hlthaff.2009.0535

Knickman, J. R., \& Snell, E. K. (2002). The 2030 problem: Caring for aging baby boomers. Health Services Research, 37(4), 849-884. https://doi.org/10.1034/j.1600-0560.2002.56.x 
Knight, J., \& Nigam, Y. (2017a). Anatomy and physiology of ageing 5: The nervous system. Nursing Times, $113(6), 55-58$.

Knight, J., \& Nigam, Y. (2017b). Anatomy and physiology of ageing 6: The eyes and ears. Nursing Times, $113(7), 39-42$.

Knowles, S. R., Apputhurai, P., O'Brien, C. L., Ski, C. F., Thompson, D. R., \& Castle, D. J. (2020). Exploring the relationships between illness perceptions, self-efficacy, coping strategies, psychological distress and quality of life in a cohort of adults with diabetes mellitus. Psychology, Health and Medicine, 25(2), 214-228. https://doi.org/10.1080/13548506.2019.1695865

Knox, J. (2009). Mirror neurons and embodied simulation in the development of archetypes and self-agency. Journal of Analytical Psychology, 54(3), 307-323. https://doi.org/10.1111/j.14685922.2009.01782.x

Lowsky, D. J., Olshansky, S. J., Bhattacharya, J., \& Goldman, D. P. (2014). Heterogeneity in healthy aging. Journals of Gerontology: Series A, 69(6), 640-649. https://doi.org/10.1093/gerona/glt162

Martinson, M., \& Berridge, C. (2015). Successful aging and its discontents: A systematic review of the social gerontology literature. Gerontologist, 55(1), 58-69. https://doi.org/10.1093/geront/gnuo37

Mendes, E. (2011, July 28). Most caregivers look after elderly parent; invest a lot of time: Majority of caregivers have been providing care for three or more years. Gallup News. https://news.gallup.com/poll/148682/caregivers-look-elderly-parent-invest-lot-time.aspx

Nyberg, L. (2017). Functional brain imaging of episodic memory decline in ageing. Journal of Internal Medicine, 281(1), 65-74. https://doi.org/10.1111/joim.12533

Petersen, R. C. (2016). Mild cognitive impairment. Continuum, 22(2), 404-418. https://doi.org/10.1212/CON.oooooooooooo0313

Potter, L., Zawadzki, M. J., Eccleston, C. P., Cook, J. E., Snipes, S. A., Sliwinski, M. J., \& Smyth, J. M. (2019). The intersections of race, gender, age, and socioeconomic status: Implications for reporting discrimination and attributions to discrimination. Stigma and Health, 4(3), 264-281. https://doi.org/10.1037/sahooooo99

Pynoos, J. (2018). The future of housing for the elderly: Four strategies that can make a difference. Public Policy and Aging Report, 28(1), 35-38. https://doi.org/10.1093/ppar/pryoo6

Reynolds, M. R., \& Niileksela, C. R. (2015). Test review: Schrank, F. A., McGrew, K. S., \& Mather, N. (2014). Woodcock-Johnson IV Tests of Cognitive Abilities. Journal of Psychoeducational Assessment, 33(4), 381-39o. https://doi.org/10.1177/0734282915571408

Rowe, J. W., \& Kahn, R. L. (1987). Human aging: Usual and successful. Science, 237(4811), 143-149. https://doi.org/10.1126/science.3299702

Schoen, C. B., \& Holtzer, R. (2017). Differential relationships of somatic and cognitive anxiety with measures of processing speed in older adults. Aging, Neuropsychology, and Cognition, 24(5), 481-495. https://doi.org/10.1080/13825585.2016.1226247

Tao, H., \& McRoy, S. (2015). Caring for and keeping the elderly in their homes. Chinese Nursing Research, 2(2), 31-34. https://doi.org/10.1016/j.cnre.2015.08.002

Taylor, D. J., Hobby, A. E., Bans, A. M., \& Crabb, D. P. (2016). How does age-related macular degeneration affect real-world visual ability and quality of life? A systematic review. BMJ Open, 6(12), Article e011504. https://doi.org/10.1136/bmjopen-2016-011504 
Tovel, H., Carmel, S., \& Raveis, V. H. (2019). Relationships among self-perception of aging, physical functioning, and self-efficacy in late life. Journals of Gerontology: Series B, 74(2), 212-221. https://doi.org/10.1093/geronb/gbxo56

United Nations, Department of Economic and Social Affairs, Population Division. (2019). Probabilistic population projections (Rev. 1). Based on, The world population prospects 2019 (Rev. 1). https://population.un.org/wpp/Download/Probabilistic/Population/

Whitbourne, S. K., \& Whitbourne, S. B. (2017). Adult development and aging: Biopsychosocial perspectives (6th ed.). Wiley.

Withaar, F. K., Brouwer, W. H., \& van Zomeren, A. H. (2000). Fitness to drive in older drivers with cognitive impairment. Journal of the International Neuropsychological Society, 6(4), 480-490. https://doi.org/10.1017/S1355617700644065

World Health Organization (Ed.). (2015). World report on ageing and health. WHO. https://www.who.int/publications/i/item/9789241565042 


\section{Appendix A}

\section{Interview Protocol for Older Couple}

Interview each older individual separately. The initial questions are posed to establish rapport and basic cognition (i.e., memory and ability to answer questions straightforwardly).

1. In what year did you emigrate to the United States?

2. Would you ever return to Ireland to live permanently? Why do you say that?

3. I hope you don't mind my asking, but how old are you?

4. What was your occupation before you retired?

5. In what year did you retire?

6. Describe a very memorable event that happened to you during your time as a [occupation]? [Follow-up question: Why is it "very" memorable for you?]

The following interview questions are substantive questions posed to garner data to answer the study's research goals (i.e., research questions):

\section{Physical Health}

1. How are you feeling today? [If the response is negative, then ask, "And why is that?"]

2. Describe how your health has been over the past month? [Follow-up question: Can you explain why?]

\section{Cognitive Function}

1. Considering recent experiences, how is your memory? [Follow-up question: Can you give some examples? or Can you describe a time when you misplaced something and what you did to find it?]

2. What do you feel are some mentally challenging tasks for you currently? [Follow-up question: In what ways have these tasks been challenging?]

3. What activities or things do you do, if anything, to keep your mind sharp and alert?

\section{Household Duties}

1. How are household tasks managed, both chores inside and outside the house? [Follow-up question: How did the household tasks become divided up in that way?]

2. How do you feel you are coping with taking care of household tasks?

\section{Finances and Administration}

1. Describe how your finances are managed? [If the respondent does not understand the question, provide the following alternate wording: How are bills paid and bank balances maintained?]

2. If you needed some cash, how would you get it?

\section{Transport}

1. If you want to go somewhere, how do you get there? [If the answer is to ask my daughter or grandson, then ask the follow-up question: How would you arrange to get there if your daughter or grandson were not available to take you?]

2. What would you do if you find yourself in unfamiliar surroundings?

\section{Appointments}

1. How are medical or dental appointments made? [Follow-up question: How is it decided that you need to see a doctor or dentist?]

2. How do you keep track of appointments? 


\section{Social Activities and Leisure Time}

1. Describe a preferred social activity in which you might engage? [Follow-up question: Would you prefer the activity to be one-on-one with another person or in a group, and why?]

2. Describe a fun leisure time activity in which you have engaged within the last week? [If the respondent cannot think of one within the last week, rephrase the question to be "within the last month."]

\section{Self-Efficacy}

1. How confident do you feel in being able to take care of yourself? [Follow-up question: What would you do in an emergency-for example, you fell and hurt yourself?]

2. How confident do you feel in being able to take care of your spouse? [Follow-up question: What might you do if your spouse fell, and you could not help them up?]

3. How do you know you are in control of your own circumstances? [If the respondent indicates they are not in control, then reword the question to How do you know you are not in control of your own circumstances?]

4. In what ways do family, friends, or neighbors assist you?

\section{General}

1. What, if any, are your current challenges in living independently? [Follow-up question: Why do you say this?]

2. What changes, if any, related to your current living arrangement have you discussed with/proposed to your spouse?

3. Is there anything else you would like to share related to any life challenges of which you are aware?

Not all follow-up questions can be predicted in advance of an interview. Therefore, some additional follow-up probing questions that can be asked to gain more depth and breadth to responses to the aforementioned questions are:

- Can you tell me more?

- How would you describe that in a different way?

- I would like to hear more about that.

- Would you clarify that for me?

- What was the effect of that incident?

- What were the consequences?

- What was your reaction to that behavior?

- Take me through your thought processes during that time. 


\section{Appendix B}

\section{Interview Protocol for Daughter and Grandson}

Interview the daughter and grandson separately. The initial question is a rapport building question:

1. Daughter: How is the pandemic affecting you and your job?

Grandson: How is your college life different for you with the pandemic?

2. Describe your relationship with your parents/grandparents?

3. In what ways do you support (or help) your parents? grandparents?

4. In what ways has your life changed as your parents/grandparents have gotten older? [Follow-up question: Can you give more examples?]

5. What are your immediate concerns related to your parents'/grandparents' safety and welfare? Long-term concerns?

6. What changes do you anticipate will be needed in your parents'/grandparents' current living arrangements? [Follow-up question: How soon do you think those will happen?]

Some additional probing questions that can be asked to gain more depth and breadth to responses to the aforementioned questions are:

- Can you tell me more?

- How would you describe that in a different way?

- I would like to hear more about that.

- Would you clarify that for me?

- What was the effect of that incident?

- What were the consequences?

- What was your reaction to that behavior?

- Take me through your thought processes during that time.

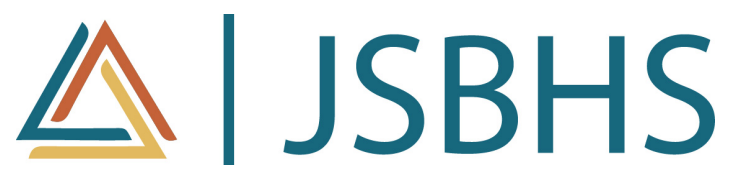

The Journal of Social, Behavioral, and Health Sciences ( $J S B H S$ ), cosponsored by the College of Health Professionals and the College of Social and Behavioral Sciences at Walden University, is a peer-reviewed, online, interdisciplinary journal focusing on theoretically based research that addresses contemporary national and international issues. JSBHS articles include peer-reviewed research reports, brief reports, comprehensive literature reviews, book reviews, and student research. 